\title{
Periodismo, militancia y contienda política
}

\author{
Journalism, Militancy and Political Conflict
}

Recepción: 27/11/2020, revisión: 04/03/2021, aceptación: 16/04/2021, publicación: septiembre de 2021

(D) Wilson Benavides Vásquez

wilsonr.benavides@gmail.com

Investigador independiente (Quito, Ecuador)

https://orcid.org/0000-0002-3640-9460

https://revistas.uasb.edu.ec/index.php/uru

(ID) Patricio Carrera Andrade patriciocarrera@yahoo.com Investigador independiente (Quito, Ecuador) https://orcid.org/0000-0001-6987-3713

DOI https: //doi.org/10.32719/26312514.2021.4.13

\section{Resumen}

Periodismo y política parecerían ser — a primera vista - dos mundos antagónicos e irreconciliables, al menos si se los mira desde la óptica de las aulas universitarias, donde se aprende que el primero denuncia las arbitrariedades y la indolencia del segundo, mientras que la política intenta ocultar sus decisiones y tergiversar sus actuaciones. Este trabajo busca desmitificar esta idea, evidenciando - a manera de hipótesis - que en Ecuador las fronteras entre ambos son bastante permeables, al punto que el periodismo se ha convertido en un escenario de contienda política en que la militancia partidista y el "ajuste de cuentas" son evidentes, lo que debilita la esfera pública y fortalece al poder político, al que dice cuestionar. El texto busca responder la siguiente pregunta: ¿hay periodismo en Ecuador o, por el contrario, este oficio - debido a una serie de condiciones estructurales y coyunturales - se ha convertido en militancia y alejado a las audiencias de los medios? A partir del contraste entre teoría y realidad, este artículo pone en diálogo a la comunicación con la sociología política y pretende constituirse en un estudio de caso de carácter cualitativo. Se utilizaron para ello varias herramientas metodológicas, como entrevistas a profundidad a periodistas en ejercicio y el análisis de contenido de cuentas de redes sociales.

\section{Abstract}

Journalism and politics would seem to be - at first glance - two antagonistic and irreconcilable worlds, at least if we look at them from the perspective of university classrooms, where we learn the journalism as a tool to denounces the arbitrariness and indolence of the government power, while politics tries hide their decisions and misrepresent their actions. This article try to evidencing the hypothesis that in Ecuador, the borders between the two are quite permeable. The point is that journalism has become a scene of political conflict where partisan militancy and the "settling of accounts" are evident, which weakens the public sphere strengthening the political power, which he claims to question. Also seeks to answer the following question: Is the journalism in Ecuador or, on the contrary, this profession - due to a series of structural and political juncture conditions - has become militancy, distancing audiences from the media? Based on contrasting theory and reality, this article creates a dialogue between communication and 
sociologic politics and intends to become a qualitative character case study using several methodological tools such as in-depth interviews with working journalists and social media content analysis.

\section{Palabras clave $\cdot$ Keywords}

Periodismo, militancia, contienda política, esfera pública.

Journalism, militancy, political struggle, public sphere.

\section{Introducción}

El ejercicio del periodismo en el Ecuador de hoy no puede entenderse fuera de un contexto de polarización social que persiste hasta la actualidad y que es el resultado de una permanente y sostenida contienda política (McAdam et al. 2005) entre el Gobierno y los medios de comunicación. Esta inició hace catorce años, cuando Rafael Correa asumió el poder en medio del colapso del sistema de partidos, resultado de un ciclo de inestabilidad política que duró diez años (1997-2007) y provocó al menos tres crisis de régimen: las caídas de Abdalá Bucaram, Jamil Mahuad y Lucio Gutiérrez.

El vacío de representación que dejó el desmantelamiento del sistema de partidos hizo que los medios de comunicación ocuparan ese espacio, aunque definidos por el Gobierno de Correa como actores políticos sin legitimidad democrática. Este ambiente de polarización ocasionó que algunos periodistas, especialmente de los medios tradicionales, fueran enfrentados, denunciados y estigmatizados por el aparato de propaganda gubernamental, que en los Enlaces Ciudadanos los englobó con el calificativo de prensa corrupta.

Además de estos aspectos coyunturales, hay elementos estructurales que fueron decisivos para legitimar estas prácticas. La propia Constitución de Montecristi -aprobada en referéndum en el año 2008 con el $63 \%$ de los votos- estableció la obligación de promulgar una Ley Orgánica de Comunicación (2013), a la que concibió no solo como un derecho sino como un servicio público, sujeto al control gubernamental a través de la Superintendencia de Comunicación (Supercom).

Esta conjunción de condiciones tanto coyunturales (colapso del sistema de partidos, hostigamiento y estigmatización gubernamental de la prensa) como estructurales (vacío de representación, marco constitucional y legal restrictivo con la prensa) definieron en la práctica el "nuevo rol" de los medios, y transformaron al periodismo de una actividad reglada (Alsina 1989) a una cultura política (Ramírez 2003) en la que los periodistas toman partido, apoyan o cuestionan abiertamente a una determinada corriente política y desbaratan con ello la separación deontológica entre información y opinión.

Esta situación se agudizó con el aparecimiento y la consolidación de las redes sociales como nuevos medios. Varios periodistas (la mayoría hostigados por el Gobierno 
de Correa) encontraron en ellas opciones para continuar ejerciendo el oficio, mediante la creación de sitios web especializados o programas independientes de noticias y opinión. En este contexto, muchos periodistas se alinearon a una u otra postura, denunciando los abusos y/o la corrupción de acuerdo al bando donde se encontraran, lo que ha desvirtuado el sentido mismo de la profesión.

Sobre la base de la contrastación entre teoría y realidad, este artículo propone un diálogo interdisciplinario entre la comunicación y la sociología política. Constituye un estudio de caso cualitativo que utilizó varias herramientas metodológicas, como entrevistas a profundidad a periodistas en ejercicio y el análisis de contenido de cuentas de redes sociales. Teóricamente, el texto propone que el periodismo no solo es un oficio sino una cultura política (Ramírez 2003), y plantea analizar esta problemática a través del encuentro entre los conceptos de contienda política (McAdam et al. 2005) y de esfera pública (Habermas 1999), provenientes de ambas disciplinas.

Este trabajo busca responder la siguiente pregunta de investigación: ¿hay periodismo en Ecuador o, por el contrario, este oficio - debido a una serie de factores- se ha convertido en militancia y alejado a las audiencias de los medios? Esquemáticamente, este documento está organizado en una introducción, una problematización teórica y las respectivas conclusiones. Los testimonios directos que varios periodistas en ejercicio aportaron para abordar esta temática sirven de herramientas metodológicas centrales.

\section{Periodismo, redes y política}

Hablar de periodismo es una tarea arriesgada, ya que pone en juego una serie de percepciones, prejuicios y mitos sobre este oficio, más aún si consideramos - a manera de hipótesis- que, en la actualidad, el periodismo en Ecuador ya no es (solo) una actividad reglada (Alsina 1989) sino una cultura política (Ramírez 2003), es decir, un conjunto compartido y disputado de percepciones, valores y prácticas que relacionan a los periodistas con el sistema político y la democracia.

Desde un punto de vista normativo, dos percepciones son fundacionales en el periodismo latinoamericano y ecuatoriano. Uno, que su labor está orientada a defender la versión liberal de la democracia y luchar contra la corrupción. Dos, que estos objetivos se consiguen cuestionando al poder político, representado principalmente en las esferas gubernamental y parlamentaria. Deontológicamente, el periodismo también se autorrepresenta como portador de dos valores socialmente relevantes, la ética y la credibilidad, mientras que desde las prácticas promueve la verificación y contrastación de la información como sus principales derroteros.

Esta argamasa de ideas y prácticas choca, sin embargo, con una realidad distinta: el posicionamiento que las redes sociales (especialmente WhatsApp, Facebook y Twitter) tienen actualmente en la sociedad, como herramientas a través de las que la gente se informa de manera inmediata y aun a costa de que sus contenidos no sean verificados, ha 
puesto en entredicho la mediación informativa (Albornoz y Albornoz 2010) que hasta hace pocos años era monopolio de los medios tradicionales (televisión, radio y prensa).

Según una encuesta de Mejía (2019) sobre el paro nacional y levantamiento popular de hace dos años en Ecuador, el 61 \% de los encuestados aseguró no creer en la información difundida por la televisión nacional durante esas protestas. En cambio, el $41 \%$ sostuvo que durante esos eventos fueron los medios digitales los que tuvieron mayor credibilidad.

Esta lógica haría suponer que el periodismo se ve obligado a abandonar las salas de redacción para adaptarse a este nuevo escenario, que curiosamente coincide con las hipótesis planteadas a finales del siglo XX en los estudios de comunicación de América Latina, que abogaron por la necesidad de pasar de la reflexión de los medios hacia el análisis de las mediaciones (Martín-Barbero 1987). Pero estas nuevas mediaciones no solo intentan descentralizar a los medios, sino que convierten a los periodistas en protagonistas de las historias, a tal punto que varias empresas de noticias han prohibido a su personal opinar en redes, como sucedió con la cadena BBC de Londres, según reportó De Miguel (2020).

En Ecuador, sin embargo, hasta el momento no se ha debatido públicamente sobre la posibilidad de tomar decisiones similares, lo que ha abonado las condiciones para que - gracias a las redes sociales - los periodistas se conviertan en activistas y viceversa. Se hace así del periodismo una perpetua contienda política (McAdam et al. 2005) y se debilita la esfera pública (Habermas 1999) que está llamado a fortalecer.

Sin embargo, la influencia de los medios tradicionales, especialmente la televisión, depende del caso que se analice. Si bien en el paro de hace dos años, como señala Mejía (2019), la gente cuestionó la información difundida por este medio, en la campaña electoral de 2021, la televisión fue el principal canal por el que la ciudadanía conoció las propuestas de los candidatos presidenciales, según la encuestadora Perfiles de Opinión.

\section{Gráfico 1}

\section{Medio por el que conoció a los candidatos, 2021}

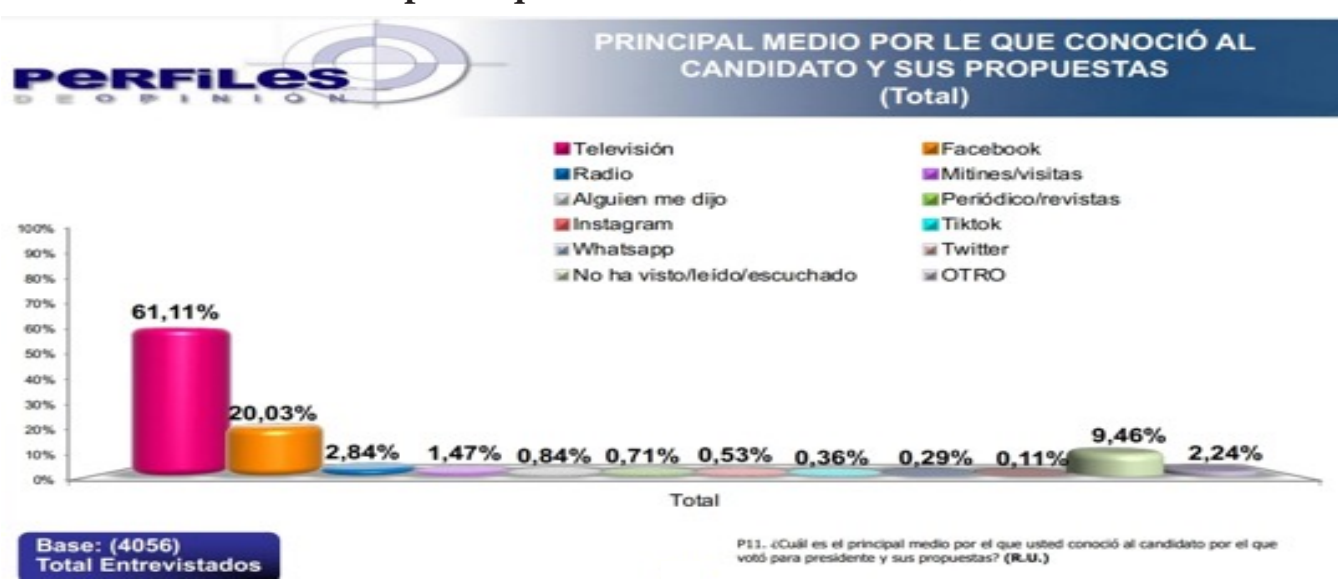

Fuente: Perfiles de Opinión 
La polarización que caracterizó a la sociedad ecuatoriana ha provocado profundos desencuentros entre los medios y las audiencias, que, pese al cambio de orientación ideológica del Gobierno de Moreno, aún no se modifican. ¿La razón? Múltiple y estructural. Por un lado, un sector de la opinión pública, apalancado en una visión homogénea de la sociedad, sostiene que esta fue influenciada por el odio de Correa hacia los medios, a los que se hostigó con un aparataje propagandístico y a través de la Ley Orgánica de Comunicación, reformada en el año 2020. Otra visión, sin embargo, concibe que la sociedad se desencantó de la opinión pública debido a que no se siente representada en sus contenidos, que - en su mayoría - reflejan las agendas del poder político de turno, en una falta de respeto al principio de pluralidad que caracteriza el pacto entre los medios y las audiencias (Grijelmo 2012).

Albornoz y Albornoz sostienen que en la opinión pública la intervención de los medios es ineludible. "Cuando los medios opinan, analizan o reflexionan sobre los asuntos públicos actúan como consignadores de legitimidad del poder político representado en el Gobierno, ya que al aplaudir o censurar una acción o decisión gubernamental, reconocen, niegan o califican la legitimidad de tal acción o decisión" $(2010,163)$.

Hardt y Negri explican el ascenso de una opinión pública global que "se extiende más allá de las instituciones políticas de representación, expandiendo una visión utópica que sostiene que los medios presentan informaciones objetivas que permiten a los ciudadanos formarse sus propias opiniones, las que a su vez son ratificadas por las encuestas de opinión difundidas por esos mismos medios" (2004, 301-3).

En este escenario, redes sociales y medios compiten por ganar espacio. Mientras las primeras apuestan por la inmediatez, los medios reiteran — de manera pública- que difunden "información verificada", una tautología impensable hasta hace poco tiempo.

\section{Contienda política e internet-centrismo}

Esta disputa entre medios y redes convierte al periodismo de un oficio reglado (Alsina 1989) en una cultura política. Ramírez sostiene que las culturas políticas son "producciones discursivas y prácticas que sedimentan diversos esquemas representacionales que producen acción política, a través de discursos y prácticas que inciden en la ampliación, reducción o cambio de la esfera de lo político y de las formas institucionales de hacer política" $(2003,441-43)$.

McAdam y sus colegas definen a la contienda política como una "interacción episódica, pública y colectiva donde interviene el Gobierno como mediador, objetivo o reivindicador. La contienda desarrolla coaliciones, interacciones estratégicas y luchas identitarias, y puede adoptar dos formas: una contenida y otra transgresiva" $(2005,6)$.

En la contienda contenida, dicen los autores, "todas las partes en conflicto estaban previamente establecidas como actores políticos constituidos; se expresa a través de medios 
convencionales de reivindicación y se concreta cuando al menos un Gobierno es uno de los reivindicadores, de los objetos de las reivindicaciones o es parte en las reivindicaciones" (8).

La contienda transgresiva, en cambio, se produce cuando "al menos algunos de los participantes en el conflicto son actores políticos recientemente autoidentificados y/o al menos alguna de las partes emplea acciones colectivas innovadoras incorporando reivindicaciones nuevas, autorrepresentaciones colectivas y/o adoptando medios que no tienen precedentes o que están prohibidos por el régimen" (8).

Ambos tipos de contienda (contenida y transgresiva) se expresan en el periodismo ecuatoriano conforme su relación — de tensión, indiferencia o cooperación- con el sistema político, pero en la actualidad ya no solo desde las salas de redacción — guiadas por pautas deontológicas-, sino desde las cuentas de redes sociales de los periodistas. Esta situación pone sobre el tapete el viejo debate entre las fronteras del periodismo informativo y el de opinión.

Desde el punto de vista sociológico, en nuestro país la contienda política tiene una larga historia que va de la mano de varios episodios de inestabilidad política que se han expresado al menos desde hace veinte años.

Tabla 1

Contiendas políticas en Ecuador durante los últimos 20 años

\begin{tabular}{|l|l|l|}
\hline Año & Episodio & Tipo de contienda \\
\hline 2005 & Caída de Lucio Gutiérrez & Mixta \\
\hline 2010 & $\begin{array}{l}30 \text { de septiembre } \\
\text { (Rafael Correa) }\end{array}$ & Contenida \\
\hline 2019 & $\begin{array}{l}\text { Paro nacional y levantamiento popular } \\
\text { en contra de Lenín Moreno }\end{array}$ & Transgresiva \\
\hline
\end{tabular}

De los tres episodios de contienda citados en la Tabla 1, en los dos primeros tuvieron incidencia directa los medios tradicionales (prensa, radio y televisión), mientras que en los dos últimos fueron decisivas las redes sociales.

Con la consolidación de internet a partir de la década de los 2000, en los países occidentales está arraigada la creencia de que una sociedad es más democrática cuando sus ciudadanos tienen mayor acceso a la información en la red, que "permite descubrir la verdad y evitar la manipulación gubernamental” (Morozov 2012, 186). 
Morozov recuerda que a finales de los años 80 y principios de los 90, tanto Alvin Toffler como Samuel Huntington postularon que "el veloz cambio tecnológico del período daría lugar a la Sociedad de la Tercera Ola, marcada por el acceso democrático al conocimiento y el advenimiento de la era de la información", donde "la tecnología de la información reemplazaba a otras dos olas, la de la agricultura y la de la industrialización, y daba paso a un nuevo período en la historia de la humanidad" (136).

Este modelo, denominado internet-centrismo, ha conducido a muchos a pensar que la información puede - por sí sola - destruir el autoritarismo, pero en la realidad también desempeña un papel fundamental a la hora de "posibilitar la propaganda, la censura y la vigilancia, los tres pilares del control autoritario, interconectándolos" (22-3). Morozov define al internet-centrismo como "la tendencia a anteponer las tecnologías de internet a los entornos en los que operan, proporcionando a los diseñadores de políticas la falsa sensación de comodidad" (156).

El internet-centrismo, dice este autor, da paso al utopismo tecnológico, "una nueva ideología que se sustenta en una lectura bastante superficial de las dinámicas políticas y de los regímenes autoritarios que da por sentado que estos se derrumbarán con celeridad cuando la información circule con libertad" (164). En el caso de la caída de Gutiérrez en el año 2005, se produjo un uso no convencional de un medio tradicional (Radio La Luna), que canalizó la protesta ciudadana a través de un repertorio innovador de movilización. El 30 de septiembre (30-S) del año 2010, en cambio, el Gobierno bloqueó la señal de los medios tradicionales, que tuvieron que enlazarse a una única transmisión del canal público Ecuador TV. En este episodio de contienda, las redes sociales actuaron como una herramienta de apoyo al Gobierno. En el paro de octubre de 2019, los medios tradicionales replicaron la versión gubernamental de la protesta, que intentó posicionar la idea (al igual que en el 30-S) de que se gestaba un golpe de Estado en su contra. Las redes, por su parte, mostraron el uso excesivo de la fuerza por parte de la Policía.

Estos tres eventos muestran la paradoja que explica Morozov al advertir que, si bien gracias a internet todo el mundo puede producir y diseminar sus opiniones y puntos de vista, "no necesariamente se garantiza una era de transparencia y honestidad, debido a que el desequilibrio de poder que existe entre las estructuras estatales y sus opositores implica que, desde el primer momento, el bando más poderoso (el Estado, generalmente) está mejor situado para aprovechar este nuevo entorno" $(2012,186)$.

En dos de los tres episodios de contienda citados, es claro que el Gobierno fue objeto de las reivindicaciones (Gutiérrez y Moreno), mientras que en el caso de Correa el Gobierno se autoconstruyó como un reivindicador. En este último episodio se produjo una contienda contenida con actores previamente establecidos, mientras que en el de Gutiérrez y en el paro de 2019 la contienda adquirió tintes transgresivos, con la intervención de los "forajidos" y de los indígenas, respectivamente. 


\title{
4. Esfera pública y militancia: La verdad es lo de menos
}

\author{
Albornoz y Albornoz desarrollan el concepto de esfera pública de Habermas (1999) \\ y explican que esta es
}

un espacio social, abierto a todos los ciudadanos, en el cual pueden reunirse para dialogar, expresar, concertar libremente y sin presiones sus opiniones sobre asuntos de interés general y construir una opinión pública que pueda ser publicitada e influir. Este ámbito, además de ser dialógico, está dirigido a la acción y precisa la ayuda de los medios para su difusión. $(2000,21)$

Desde esta perspectiva, en el Ecuador actual, ¿las redes y los medios cumplen el anhelo de Habermas de fomentar una democracia deliberativa en la esfera pública o, por el contrario, se han convertido en espacios de contienda política que han desnaturalizado al periodismo?

Esta pregunta es central para intentar comprender la situación del oficio en nuestro país, pues si bien la esfera pública promueve la presencia de innumerables perspectivas sobre los temas que surgen de la sociedad civil, la polarización social la ha hiperpolitizado, y ha alejado a los medios de las audiencias. Para ejemplificar esta situación, hemos escogido un episodio de contienda política que se expresó a propósito del juicio político en contra de la hoy exministra de Gobierno, María Paula Romo, en noviembre del año 2020.

\section{Gráfico 2}

\section{Tuit de la periodista Tania Tinoco}

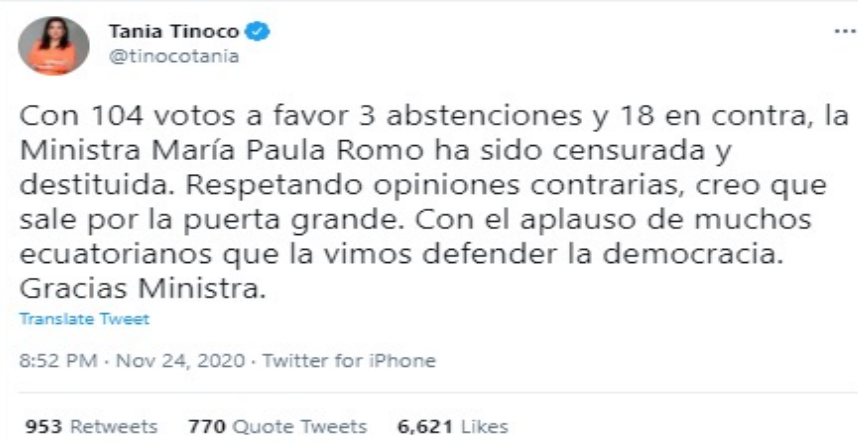

Fuente: Twitter

El Gráfico 2 contiene una captura de pantalla de la cuenta personal de Twitter de la periodista de la cadena Ecuavisa Tania Tinoco. "Creo que sale por la puerta grande, con el aplauso de muchos que la vimos defender la democracia”, concluye su texto. Por su parte, el exeditor de la sección Política del diario El Comercio y fundador del portal 4Pelagatos mencionó: 


\section{Gráfico 3}

\section{Tuit del periodista Martín Pallares}

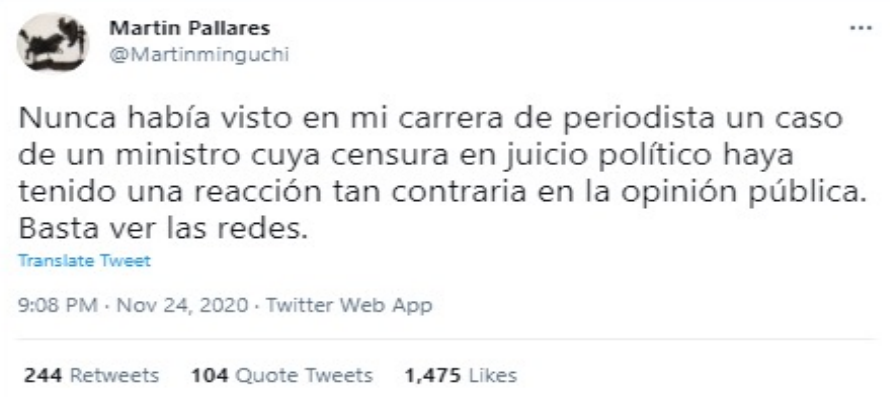

Fuente: Twitter

Es claro que el tuit de Martin Pallares constituye un relato desde su propio contexto, que refleja las opiniones de los seguidores que tiene en esa red social. Por ello, referirse a que (toda) la opinión pública ha tenido una reacción adversa a ese juicio político es una falacia. Del otro lado, Orlando Pérez, exeditor de El Telégrafo y presentador del programa "En clave política", de la cadena Telesur, escribió lo siguiente:

\section{Gráfico 4}

\section{Tuit del periodista Orlando Pérez}

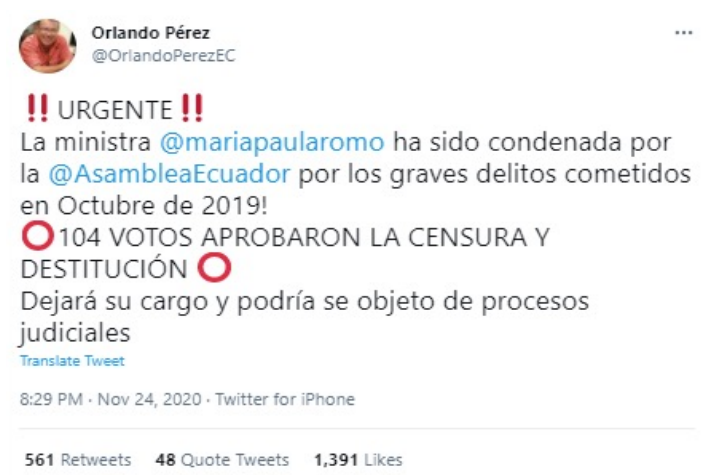

Fuente: Twitter

$\mathrm{Al}$ incluir el término "graves delitos" y la frase "podría ser objeto de procesos judiciales", este periodista - al igual que Tinoco y Pallares- mezcla en el mismo texto información y opinión, asumiendo una posición política que - en teoría - no le corresponde.

Para el ex editor general del diario El Comercio y actual director del portal Código Vidrio, Arturo Torres, hay una tendencia a escala mundial del periodista opinólogo, cuyo 
arquetipo se ha potenciado por el uso de las redes sociales, pues difunden sus mensajes como expertos en los temas de los que hablan y en el campo político, con premisas incuestionables. "Al mismo tiempo que opinan a mansalva en redes sociales, son gestores políticos que representan a determinados movimientos. Eso no tiene nada que ver con el periodismo" (Torres 2020, entrevista personal).

Pero ¿qué sucede cuando los medios y los periodistas pierden la autonomía y la distancia respecto del poder político o económico? Torres es directo al indicar que en esta espiral hay actores como Carlos Vera, que apoya al Partido Social Cristiano (PSC) sin condiciones, al igual que Orlando Pérez, que respalda directamente a la Revolución Ciudadana. "Estas personas son profesionales que estudiaron periodismo, pero ahora ejercen una actividad proselitista que nada tiene que ver con el oficio", puntualiza, y advierte que esto "genera desconfianza de la sociedad y ha desgastado la imagen del periodismo con la gente, ya que al ver este papel ambiguo, no sabe cuál es el rol del periodista" (Torres 2020, entrevista personal).

La editora política del portal GK, María Sol Borja, coincide con Torres y sostiene que la polarización hace que la gente, incluidos los periodistas, pierdan un poco la perspectiva del rol que tiene en la sociedad. La comunicadora cree que toda persona tiene derecho a opinar lo que quiera, pero si haces periodismo, "tienes que dejar de opinar desde el estómago o convertirte en cheerleader de las acciones de los funcionarios" (Borja 2020, entrevista personal).

Albornoz y Albornoz aclaran que la esfera pública debe reflejar

una pluralización segmentada que alude tanto a la multiplicidad de públicos (movimientos sociales, asociaciones de voluntarios, grupos de interés, etc.) con propósitos y enfoques definidos, como a los que integrarían un público de públicos civil y no especializado, que acepta la interacción comunicativa de miembros de diferentes esferas funcionales o grupos sociales. (2010, 22-3; las cursivas son nuestras)

Esta pluralización segmentada de la esfera pública, permite, a su vez, que cumpla su papel de "mediación necesaria entre la sociedad civil, el Estado y el sistema político, y en esa medida, se convierta en un espacio insustituible de constitución democrática de la opinión y de la voluntad colectivas" (22). Sin embargo, la hiperpolitización de la esfera pública en Ecuador bloquea esa posibilidad, toda vez que esos espacios (Twitter, especialmente) se han convertido en escenarios de contienda política, dejando de lado su esencia.

Este fenómeno, sin embargo, adquiere un carácter paradójico, pues si bien el INEC (2014) señala que para ese año un 41,4 \% de ecuatorianos mayores de 12 años tenía una cuenta en redes sociales (97,9 \% en Facebook; 33,1 \% en WhatsApp y 20,4 \% en Twitter), no precisamente la utilizaba para hablar u opinar de política. Según Moncagatta et al. (2020), solo el $2 \%$ de los usuarios habla de política en Twitter, el 22,3 \% en Facebook y el 16,5 \% en WhatsApp. De allí que los líderes de opinión citados en este documento no necesa- 
riamente tengan el alcance o la incidencia que imaginan, más allá de esta esfera pública hiperpolitizada pero limitada, que han construido de espaldas a las audiencias.

Aunque el modelo dialogal de la democracia deliberativa diseñado por Habermas (1999) parecería a primera vista hacerse realidad en las redes sociales, desde una perspectiva deontológica, en Ecuador esta esfera pública hiperpolitizada pero limitada es el escenario de lo que Arendt denomina verdad factual, donde "los hechos precisan de los testimonios generando una tendencia a transformarlos en opiniones y desdibujando la frontera entre ambos" (2018, 34-5). Este divorcio entre los hechos y las opiniones, inspirado por pasiones e intereses diversos, "es presa fácil del campo de la política, que tiende siempre a negar o tergiversar la verdad factual" (90).

Desde esta óptica, es bastante probable que, siguiendo a Morozov (2012), la desnaturalización de la esfera pública y la consecuente desconexión con las audiencias fortalezcan en el público una idea de la democracia que nada tiene que ver con la que estos periodistas promueven en Twitter

\section{Conclusiones}

Es el acceso a la información a través de las redes sociales y no únicamente la estrategia política de un Gobierno en particular contra los medios lo que provoca la deslegitimación de estos últimos. Al contar con una comunicación multidireccional e innumerables fuentes al mismo tiempo, las audiencias pueden producir, difundir y consumir información de manera independiente a la que difunden los medios tradicionales, sin que esto signifique necesariamente un desplazamiento definitivo de la influencia que estos, especialmente la televisión, ejercen sobre la ciudadanía.

Contrario a lo que postula la democracia deliberativa de Habermas (1999), las redes sociales en Ecuador no se han consolidado precisamente como el espacio de la esfera pública, donde todo el mundo puede opinar sin coerción y en igualdad de condiciones sobre los temas planteados por la sociedad civil. Se ha convertido, en cambio, en un escenario de contienda política gobernada por la verdad factual, la que convierte a los hechos en opiniones, lógica a la que fácilmente se adhieren los periodistas.

Esta esfera pública local, aunque hiperpolitizada, tiene un alcance limitado, toda vez que las audiencias - salvo menos del $10 \%$ - no se informan de temas políticos por Twitter, lo que convierte a esta red social en una suerte de espejismo de la opinión pública. Es una falacia afirmar que la opinión pública en temas de política se reduce o limita a Twitter.

Los periodistas se convierten en militantes porque confunden - especialmente en sus redes sociales- su autopercepción como defensores de la democracia con la práctica del activismo partidista, en un relato que abiertamente mezcla información con opinión. Esta situación desnaturaliza al periodismo ahondando el abismo entre las audiencias y los medios. Al mismo tiempo, ciertos periodistas se alinean al poder gubernamental de 
turno por diferentes razones, que podrían ir desde conservar el trabajo, acceder a nichos de dirección en instituciones del Estado o impulsar intereses personales para ingresar a la política.

\section{Referencias}

Albornoz, Consuelo, y María Belén Albornoz. 2010. La esfera pública en la blogósfera política ecuatoriana. Quito: Flacso Ecuador.

Alsina, Miguel. 1989. La construcción de la noticia. Barcelona: Paidós.

Arendt, Hannah. 2018. Verdad y mentira en la política. Barcelona: Página Indómita.

De Miguel, Rafa. 2020. “La BBC prohibirá a sus periodistas opinar en Twitter”. El País. 4 de septiembre. https://bit.ly/3wtgww9 .

Grijelmo, Álex. 2012. La información del silencio. Cómo se miente contando hechos verdaderos. Madrid: Taurus.

Habermas, Jürgen. 1999. La inclusión del otro. Estudios de teoría política. Barcelona: Paidós.

Hardt, Michael, y Antonio Negri. 2004. Multitud. Guerra y democracia en la era del imperio. Buenos Aires: Debate.

Martín-Barbero, Jesús. 1987. De los medios a las mediaciones. Comunicación, cultura y hegemonía. Barcelona: Gustavo Gili.

McAdam, Doug, Sidney Tarrow, y Charles Tilly. 2005. Dinámica de la contienda política. Barcelona: Cambridge University Press.

Mejía, Jheovany. 2019. “Informe especial post protestas”. Eureknow. 28 de octubre. https://bit.ly/3bJcS9x.

Moncagatta, Paolo, Arturo Moscoso, Simón Pachano, J. Daniel Montalvo y Elizabeth Zechmeister. 2020.

Cultura política de la democracia en Ecuador y las Américas. 2018/19. Tomándole el pulso a la democracia. Quito: Vanderbilt University. https://bit.ly/3bPqG29.

Morozov, Evgeny. 2011. El desengaño de internet. Los mitos de la libertad en la red. Barcelona: Destino.

Ramírez, Franklin. 2003. "Explorando en un agujero negro. Apuntes para una crítica de las visiones dominantes sobre cultura política en el Ecuador”. En Antología. Democracia, gobernabilidad y cultura política, compilado por Felipe Burbano de Lara, 423-49.Quito: Flacso Ecuador. 